\title{
К ВОПРОСУ ОБЕСПЕЧЕННОСТИ СФЕРЫ ВЫСШЕГО ПРОФЕССИОНАЛЬНОГО ОБРАЗОВАНИЯ В РОССИЙСКОЙ ФЕДЕРАЦИИ СТРАТЕГИЯМИ РАЗВИТИЯ ЭКОНОМИЧЕСКОЙ БЕЗОПАСНОСТИ
}

\author{
(c) 2019 Соколова Екатерина Иосифовна \\ кандидат филологических наук, доцент кафедры иностранных языков № 3 \\ Российский экономический университет им. Г.В. Плеханова, Россия, Москва \\ E-mail:kafmkk@mail.ru
}

В статье автора рассматривается вопрос обеспеченности сферы высшего профессионального образования в Российской Федерации стратегиями развития экономической безопасности. Объектом исследования выступила система высшего профессионального образования в Российской Федерации, а предметом - стратегии развития экономической безопасности в данной системе. Теоретическое и методологическое значения исследования заключены в расширении представлений о взаимосвязи стратегий развития экономической безопасности и сферы высшего профессионального образования. Практическое значение исследования связано с формированием распределительного поля стратегической вовлеченности сферы высшего профессионального образования в Российской Федерации в процесс обеспечения экономической безопасности.

Ключевые слова: Стратегия, экономическая безопасность, развитие, высшее профессиональное образование, сфера, Российская Федерация.

Система стратегического планирования, как эффективный инструмент развития, достаточно давно используется во многих сферах экономической деятельности в Российской Федерации [3, с.67]. Так, например, по данным компании Ernst\&Young (рис. 1), наибольший уровень проникновения данного инструмента (50\% и более) на начало 2019 года (усредненные данные) имел место для финансовой сферы (порядка 81,9\%), сфер производства (порядка 76,5\%) и информационных технологий (порядка 69,7\%) [9]. Для прочих сфер (включая сферу образования) в Российской Федерации данный показатель на указанную дату составил порядка 29,5\%.

Сама система стратегического планирования в Российской Федерации, проникающая в различные сферы экономической деятельности, представлена, в том числе, множеством стратегий $[2,4,5]:$ от оптимизации человеческих ресурсов до развития экономической безопасности.

Актуальное состояние некоторых элементов системы [1, 3, 4] стратегического планирования [8, с.449] в экономическом пространстве Российской Федерации, оцененное по темпам роста $[7$, 8] внедряемых стратегий за последние пять лет, приведено на рисунке 2.

Исходя из того, что в экономическом пространстве Российской Федерации [4, 5] высокую актуальность приобретают вопросы стратегического внедрения системы экономической безо- пасности (для них имеет место максимальный темп роста со значением порядка $57,8 \%$ ), далее рассмотрим текущее состояние данного вопроса в сфере высшего профессионального образования в Российской Федерации за анализируемый период.

Основным показателем [7, с.703], способным охарактеризовать текущее состояние анализируемого вопроса, является уровень обеспеченности, отражающий в количественном относительном выражении наличие необходимых стратегий у того или иного объекта в выбранный период времени:

$$
\text { уо }=\sum_{i=1}^{N} \text { уову }_{i} \times \text { увВУз }_{i}
$$

где: УО - средний уровень обеспеченности высших учебных заведений в Российской Федерации за выбранный промежуток времени стратегиями развития экономической безопасности;

УO - измеряется в процентах (округлением до сотых / при необходимости сравнения равных значений в сотых доля - до тысячных);

УО - изменяется от 0 (минимально возможное значение среднее значение за анализируемы период времени) до 100\% (максимально возможное среднее значение за анализируемый 


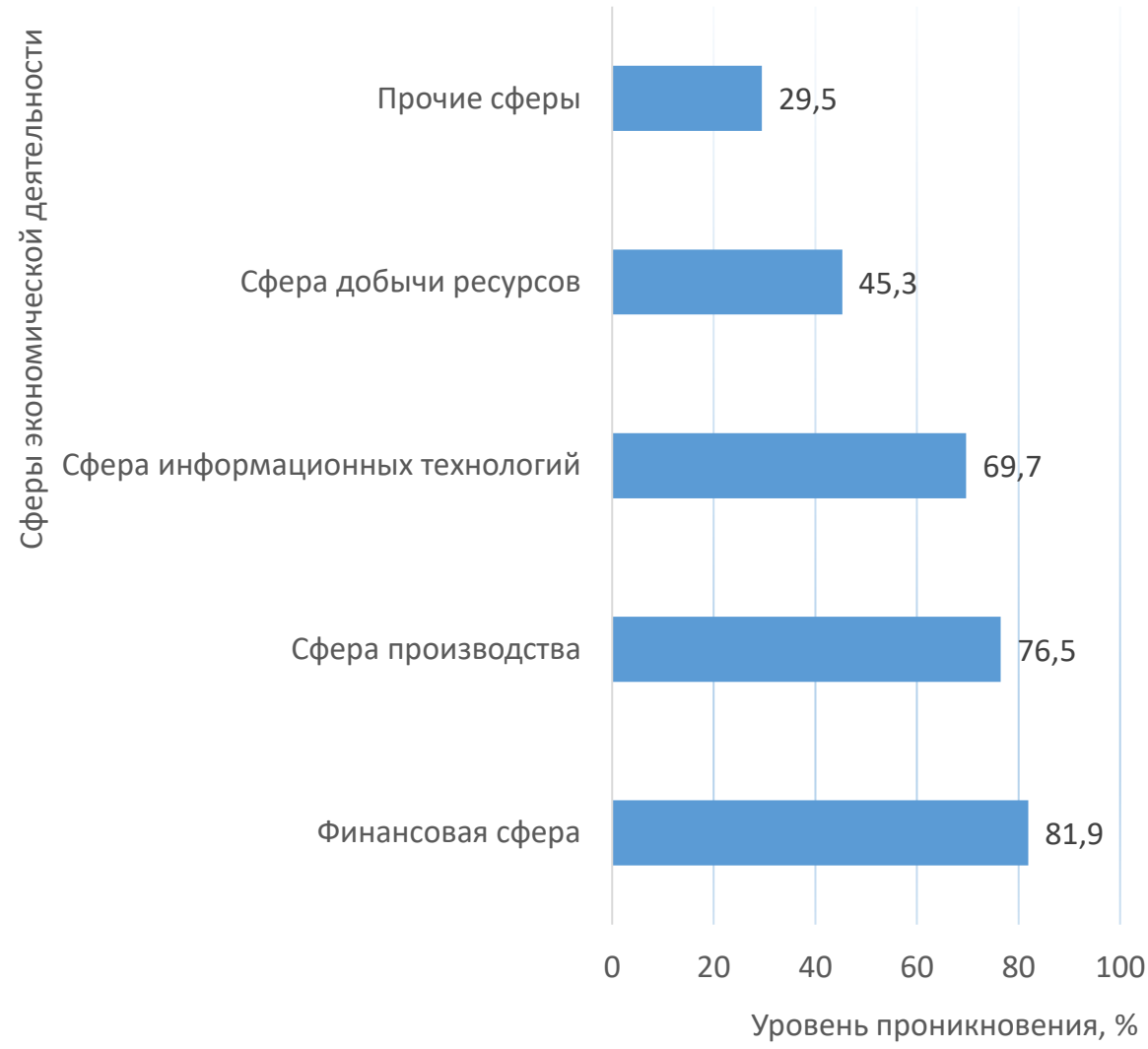

Puc. 1. Уровни проникновения системы стратегического планирования в различные сферы экономической деятельности в Российской Федерации по состоянию на 01.01.2019 года [9]

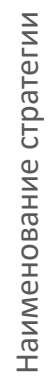

Прочие стратегии

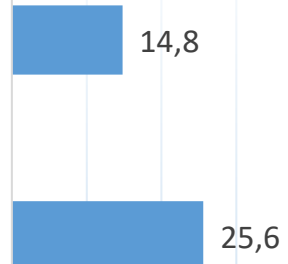

человеческих ресурсов

25,6

Стратегия ресурсосбережения

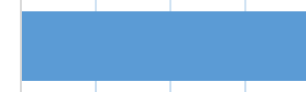

38,5
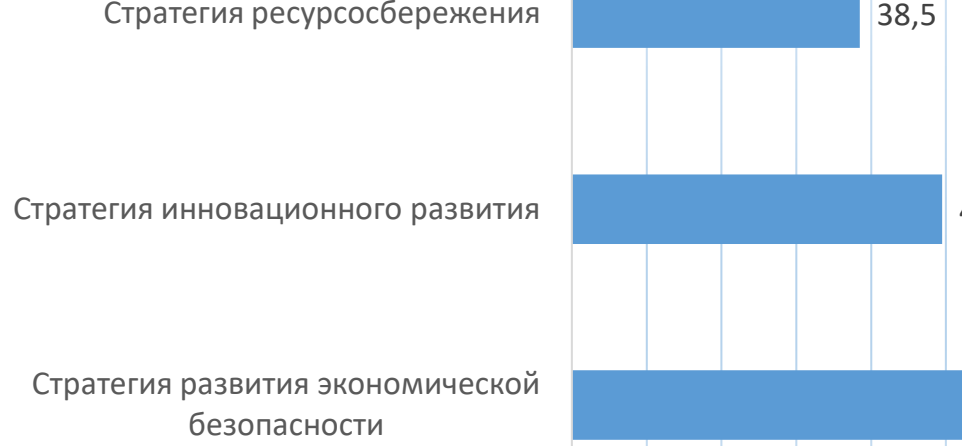

49,5
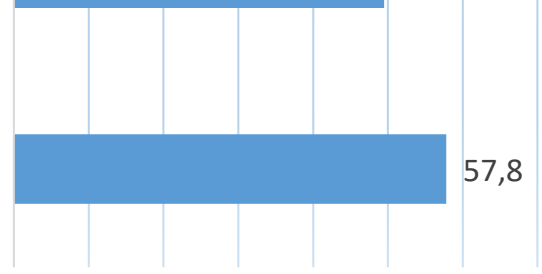

$\begin{array}{llllllll}0 & 10 & 20 & 30 & 40 & 50 & 60 & 70\end{array}$

Темп роста внедрения стратегии \%

Puc. 2. Оцененное по темпам роста актуальное состояние внедрения некоторых стратегий в экономическое пространство Российской Федерации за 2014-2018 годы [9] 
период времени);

УОВУЗ $_{i}$ - рейтинговая оценка уровня обеспеченности і-го высшего учебного заведения в Российской Федерации за выбранный промежуток времени стратегией развития экономической безопасности (измеряется в процентах с округлением до сотых). Оценка осуществляется экспертным методом (группа экспертов) в интервале от 0\% (у і-го высшего учебного заведения в Российской Федерации отсутствует стратегия развития экономической безопасности) до $100 \%$ (у і-го высшего учебного заведения в Российской Федерации присутствует в полном объеме стратегия развития экономической безопасности);

i - индекс высшего учебного заведения в Российской Федерации;

$\mathrm{N}$ - количество высших учебных заведений (при необходимости - выборочное количество высших учебных заведений на основе мнения группы экспертов / прочего мнения);

$\mathrm{N}$ - целое положительное число;

УВВУ $_{i}$ - удельный вес і-го высшего учебного заведения в совокупной массе высших учебных заведений в Российской Федерации (рассчитывается по формуле 2):

$$
\mathrm{yBBУ}_{i}=\frac{\mathrm{CK}_{i}}{\mathrm{CК \Pi}}
$$

где: УВВУЗ $_{i}$ - удельный вес і-го высшего учебного заведения в Российской Федерации за анализируемый период времени;

УВВУЗ $_{i}$ - измеряется в дробных положительных числах (безразмерная величина с округлением до тысячных величин);

УВВУ $3_{i}$ - изменяется от 0 до 1 ;

$\mathrm{CK \Pi}_{i}-$ среднесписочное количество персонала высшего учебного заведения в Российской Федерации за анализируемый период времени (измеряется в целых положительных единицах людях). Рассчитывается на основе данных официальной статистки высшего учебного заведения или на основании персонального запроса в высшее учебное заведение на использование его внутренних отчетных данных (в случае отсутствия ответа - расчет показателя производится на основе мнения экспертов);

СКП - среднесписочное количество персонала во всех анализируемых высших учебных заведениях в Российской Федерации за анализируемый период времени (измеряется в целых положительных единицах - людях). Рассчитывается на основе данных официальной статистки высшего учебного заведения или на основании персонального запроса в высшее учебное заведение на использование его внутренних отчетных данных (в случае отсутствия ответа расчет показателя производится на основе мнения экспертов).

Результаты исследования данного показателя для высших учебных заведений в Российской Федерации за последние пять лет (2014-2018 годы) приведены на рисунке 3.

Из рисунка 3 можно увидеть следующее:

- за анализируемый период времени значение исследуемого показателя изменилось на 7,83 единицы или в 1,80 раза;

- изменение исследуемого показателя носило относительно равномерный характер (незначительное отклонение имело место в 2016 году - здесь можно увидеть некоторый сдвиг в меньшую сторону от 12,55\% в 2015 году до 11,38\% в 2016 году; к 2017 году положение сдвига было нивелировано и значение анализируемого показателя увеличилось) с тенденцией к увеличению его значения;

- минимальное значение исследуемый показатель за 2014-2018 годы имел место в начале исследуемого периода (2014 год) - 9,73\%;

- максимальное значение исследуемый показатель за 2014-2018 годы имел место в конце исследуемого периода (2018 год) - 17,56\%;

- изменение значения исследуемого показателя во времени (2014, 2015, 2016, 2017 и 2018 годы) наиболее оптимально характеризует полиномиальная кривая третьего уровня;

- значение коэффициента детерминации (R2) находится выше 0,8 единицы, что свидетельствует о значительном изменении результата (УО), ввиду изменения периода времени в относительном выражении $(1,2,3,4$ и 5 период соответственно);

- прогноз на изменение значения исследуемого показателя на ближайшие два года - положительный (приблизительное прогнозное значение на 2019 год: 26,58\%).

По итогам можно сделать вывод об относительно низкой обеспеченности высших учебных заведений Российской Федерации стратегиями развития экономической безопасности*. При-

\footnotetext{
* Для справки: значение анализируемого показателя в 2018 году равнялось: для США 68,39\%; для Германии 58,98\%; для Японии 49,37\%.
} 


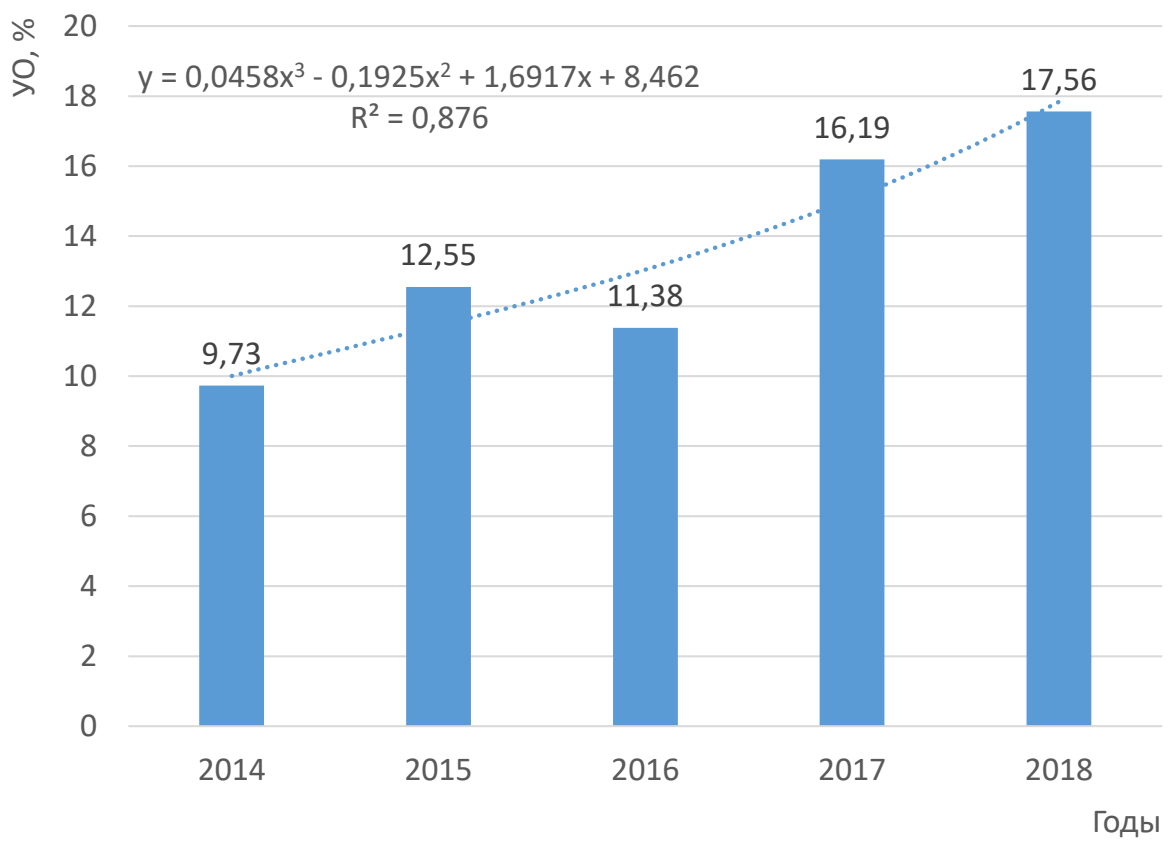

Рис. 3. Значения показателя обеспеченности сферы высшего профессионального образования в Российской Федерации стратегиями развития экономической безопасности за 2014-2018 годы

чины сложившейся ситуации, в основном, связаны с недостатком финансирования данного процесса на федеральном и региональном уровнях и отсутствием необходимой и эффективно адаптированной методической базы в области разработки и реализации специализированных стратегических планов.

Для разрешения сложившейся ситуации можно предложить изменить централизованный путь, влияющий на локальные высшие учебные заведения, например, через федеральную целевую программу или систему грантов.

Результаты исследования, по мере изучения анализируемого вопроса в области стратегического планирования высших учебных заведений, могут быть использованы на федеральном и региональном уровнях для решения широкого круга задач теоретической и практической плоскости.

\section{Библиографический список}

1. Бигжанова А. М., Безверхая О.Н. Угрозы экономической безопасности национальной экономики России: проявления, нейтрализация / А.М. Бигжанова, О.Н. Безверхая // Молодой ученый - Казань: Изд-во «Молодой учёный» - 2018. - № 13.- С. 221-225.

2. Клокова М.А. Экономическая безопасность предприятия как необходимый элемент управления предприятием в современной рыночной экономике / М.А. Клокова // Системное управление - Саранск: Изд-во «Национальный исследовательский Мордовский государственный университет им. Н.П. Огарёва» - 2014.№ 4.- С. 53-58.

3. Мясоедов С.А. Оценка уровня устойчивого экономического развития и экономическая безопасность отраслей минерально-сырьевого комплекса России / С.А. Мясоедов // Экономические науки - Москва: Изд-во ООО «24-Принт» - 2018. - № 12.- С. 65-69.

4. Николаева Е.А., Григорьева И.В. и др. К аспектам влияния оценки эффективности деятельности профессорско-преподавательского состава высшего учебного заведения на укрепление экономической безопасности Российской Федерации / Е.А. Николаева, И.В. Григорьева, И.С. Казимирова, Е.И. Соколова // Экономические науки - Москва: Изд-во ООО «24-Принт», 2019. - № 3.- С. 62-67.

5. Новицкий Н.А. Экономическая безопасность новой индустриализации: критерии и индикаторы / Н.А. Новицкий // Экономические науки - Москва: Изд-во ООО «24-Принт», 2013. - № 5. - С. 7-11. 
6. Сушкова И. А., Бондаренко А.А. Инновационная модель обеспечения системы экономической безопасности предприятия / И.А. Сушкова, А.А. Бондаренко // Информационная безопасность регионов - Саратов: Издво «Саратовский социально-экономический институт (филиал) федерального государственного бюджетного образовательного учреждения высшего образования «Российский экономический университет им. Г.В. Плеханова» - 2017. - № 3-4.- С. 63-67.

7. Allcott, H., and C. Sunstein (2015). «Regulating Internalities». Journal of Policy Analysis and Management 34, no. 3: 698-705.

8. Buzan, B (1991). «New Patterns of Global Security in the Twenty-First Century». International Affairs (Royal Institute of International Affairs 1944): 431-451.

9. Компания E\&Y [Электронный ресурс]: аналитические материалы - Официальный сайт компании «Ernst \& Young», 2019.- Режим доступа: https://www.ey.com 